\title{
Neuronal Correlates for Preparatory Set Associated with Pro-Saccades and Anti-Saccades in the Primate Frontal Eye Field
}

\author{
Stefan Everling and Douglas P. Munoz \\ Medical Research Council Group in Sensory-Motor Neuroscience, Department of Physiology, Queen's University, \\ Kingston, Ontario K7L 3N6, Canada
}

Diversity in behavioral responses to sensory stimuli has been attributed to variations in preparatory set. Variability in oculomotor responses toward identical visual stimuli has been well documented, but the neuronal processes underlying this variability are poorly understood. Here, we report evidence for set-related activity for saccadic eye movements in single neurons in the frontal eye field (FEF) in monkeys trained on a task in which they either had to look toward a visual stimulus (prosaccade) or away from the stimulus (anti-saccade) depending on a previous instruction. A portion of FEF neurons were identified as neurons projecting directly to the superior colliculus (SC) with antidromic activation techniques. Saccade-related neurons in the FEF had lower prestimulus and stimulus-related activity on anti-saccade trials compared with pro-saccade tri- als. The level of prestimulus activity correlated with saccadic reaction times, express saccade occurrence, and errors in the anti-saccade task. In addition, saccade-related activity in the FEF was higher for pro-saccades than for anti-saccades. These results demonstrate that the direct descending pathway from the FEF to the SC carries preparatory set-related activity for pro-saccades and anti-saccades. The results also provide insights into the neuronal basis of variations in saccadic reaction times and in the control of the prepotent response to glance to a flashed stimulus.

Key words: frontal eye field; eye movement; anti-saccade; motor preparation; saccade; frontal lobe; superior colliculus; monkey
One of the most remarkable behavioral features of humans and animals is the moment to moment variability of responses to identical sensory stimuli (Sherrington, 1910; Kupfermann et al., 1974; Wise et al., 1996a). This flexibility, evident in the type of the response and in its reaction time, has been attributed to variations in readiness to make a response or in intention to perform a particular task, both commonly referred to as preparatory set (Hebb, 1972; Evarts et al., 1984). For the oculomotor saccadic system, variability in reaction times is well documented. Saccadic reaction time (SRT) toward a flashed visual stimulus (pro-saccades) can range from 90 to $>400 \mathrm{msec}$ with a mean of $\sim 200 \mathrm{msec}$ (Westheimer, 1954). Although the common response is to look toward a suddenly flashed visual stimulus (Hess et al., 1946; Ingle, 1973), humans (Hallett, 1978; Hallett and Adams, 1980; Fischer and Weber, 1992) and monkeys (Schlag-Rey et al., 1997; Amador et al., 1998; Everling et al., 1998a, 1999) can be instructed in advance not to look to the stimulus but instead to look to the opposite side, in a task that is known as the antisaccade task (for review, see Everling and Fischer, 1998).

Neurophysiological evidence for set-related activity in the anti-

\footnotetext{
Received July 13, 1999; revised Sept. 20, 1999; accepted Oct. 14, 1999.

This work was supported by the Medical Research Council of Canada and the EJLB Foundation. S.E. was supported by a postdoctoral fellowship from the Deutsche Forschungsgemeinschaft. D.P.M. is a research scholar of the EJLB foundation and a Medical Research Council of Canada Scientist. We are grateful to I. T. Armstrong, B. D. Corneil, J. Dafoe, M. D. Dorris, and M. A. Meredith for helpful comments. We thank A. H. Bell for participating in part of the data collection. We are especially grateful to A. Lablans for her excellent assistance in training and care of animals.

Correspondence should be addressed to Dr. Douglas P. Munoz, Department of Physiology, Queen's University, Kingston, Ontario K7L 3N6, Canada. E-mail: doug@eyeml.queensu.ca.

Dr. Everling's present address: Department of Experimental Psychology, Oxford University, South Parks Road, Oxford OX1 3UD, UK.

Copyright (C) 1999 Society for Neuroscience $\quad 0270-6474 / 00 / 200387-14 \$ 15.00 / 0$
}

saccade task has been found in the dorsolateral prefrontal cortex (DPC) and in the supplementary eye field (SEF). Many SEF neurons are more active on anti-saccade trials compared with pro-saccade trials (Schlag-Rey et al., 1997). Furthermore, on anti-saccade trials when the monkey failed to suppress an eye movement, the activity of many neurons in the DPC (Funahashi et al., 1993) and in the SEF (Schlag-Rey et al., 1997) was similar to that associated with pro-saccades.

Another region of frontal cortex likely to display preparatory set activity for saccades is the frontal eye field (FEF) in the rostral bank of the arcuate sulcus (for review, see Schall, 1997; Schall and Thompson, 1999). A critical involvement of the FEF in the anti-saccade task has been supported by human lesion (Guitton et al., 1985) and brain-imaging studies (O’Driscoll et al., 1995; Sweeney et al., 1996; Doricchi et al., 1997). Moreover, acute inactivation of the FEF leads to a prolongation of SRTs (Sommer and Tehovnik, 1997; Dias and Segraves, 1999). In addition to visual and saccade-related responses (Bruce and Goldberg, 1985), many FEF neurons display low-frequency prestimulus activity (Bruce and Goldberg, 1985; Schall, 1991) that could be correlated with SRTs (Dias and Bruce, 1994). To address the question whether variations in the activity of FEF neurons reflect differences in preparatory set, we recorded the activity of single FEF neurons while monkeys performed a task with randomly interleaved pro- and anti-saccade trials.

Previous studies have shown that the variability in discharge of neurons in the superior colliculus (SC) reflects differences in preparatory set (Basso and Wurtz, 1997, 1998; Dorris et al., 1997; Dorris and Munoz, 1998; Everling et al., 1999). To determine whether the direct pathway from the FEF to the SC (Leichnetz et al., 1981; Fries, 1984; Segraves and Goldberg, 1987; Stanton et al., 1988; Lynch et al., 1994) carries set-related activity, we used 
antidromic activation techniques to identify corticotectal neurons in many experiments.

\section{MATERIALS AND METHODS}

Electrophysiology. All experimental procedures were in accordance with the Canadian Council on Animal Care policy on the use and care of laboratory animals and approved by the Queen's University Animal Care Committee. Surgical, electrophysiologi$\mathrm{cal}$, and data acquisition methods were described previously $(\mathrm{Mu}-$ noz and Istvan, 1998; Everling et al., 1999). Briefly, two male monkeys (Macaca mulatta) were implanted with scleral search coils, a head-restraining device, and two recording chambers, one centered above the arcuate sulcus (right hemisphere in monkey a and left hemisphere in monkey b) for neuron recordings in the FEF and one centered on the midline and tilted $38^{\circ}$ posterior of vertical for microstimulation of the SC. These were the same animals that we used for single neuron recordings in the SC in the same paradigm (Everling et al., 1999). Single neurons were recorded in the rostral bank of the arcuate sulcus. The FEF region was first identified by low-threshold microstimulation $(<50 \mu \mathrm{A}$ at $100 \mathrm{msec}, 300 \mathrm{~Hz}, 0.3 \mathrm{msec}$ biphasic pulses) that reliably elicited a contraversive saccade. The intermediate layers of the SC were identified by neuronal recordings and microstimulation (Everling et al., 1999). For antidromic activation of corticotectal neurons, single biphasic current pulses $(0.1-0.3 \mathrm{msec})$ were passed through one of four chronically implanted monopolar tungsten microelectrodes inserted into the intermediate layers of the ipsilateral SC and an indifferent electrode. Electrodes were implanted in the SC for 2-4 weeks. One electrode was placed at $<2^{\circ}$ eccentricity on the collicular motor map; the other three electrodes were placed between 10 and $20^{\circ}$ eccentricity $\left(\sim 45^{\circ}\right.$ up, approximately horizontal, $\sim 45^{\circ}$ down) on the collicular motor map (Robinson, 1972). The responses to SC stimulation that were recorded in the FEF were digitized on a hard drive at $30 \mathrm{kHz}$ (DataWave Technologies) for subsequent off-line analysis. We stored the epoch spanning $5 \mathrm{msec}$ before to $10 \mathrm{msec}$ after the onset of stimulation. Single biphasic stimulation pulses were delivered while the activity of a single FEF neuron was monitored (Fig. 1). The current threshold for antidromic excitation ranged from 15 to $1500 \mu \mathrm{A}$, with a mean of $370 \mu \mathrm{A}$ (median, $200 \mu \mathrm{A})$. Antidromic responses were verified with several criteria, including fixed threshold, fixed latency, ability to follow high-frequency twin pulses, and collision testing (Lipski, 1981). Stimulation pulses were not delivered during recordings of the behavioral paradigms.

Behavioral task. Monkeys were trained on a task with randomly interleaved pro- and anti-saccade trials. Details of the experimental setup and paradigms were described previously (Everling et al., 1999). Briefly, visual stimuli were back-projected onto a tangent screen by light-emitting diodes (red and green, $0.3 \mathrm{~cd} / \mathrm{m}^{2}$ ). Each trial of the pro-/anti-saccade paradigm (Fig. $2 A, B$ ) began with the presentation of a central fixation point (FP) on the screen. The monkey was required to look at it and maintain fixation for 700-900 msec. A red FP signaled a pro-saccade trial (Fig. $2 A$ ), and a green FP signaled an anti-saccade trial (Fig. 2B). On half of the trials, the FP remained illuminated throughout the trial (overlap condition). On the other half of the trials (gap condition), the FP disappeared $200 \mathrm{msec}$ (gap period) before stimulus presentation. The gap condition was included to increase the variability of behavioral responses (Fischer and Weber, 1992; Everling et al., 1998a; Munoz et al., 1998). An eccentric red visual stimulus was then presented pseudorandomly with equal proba-

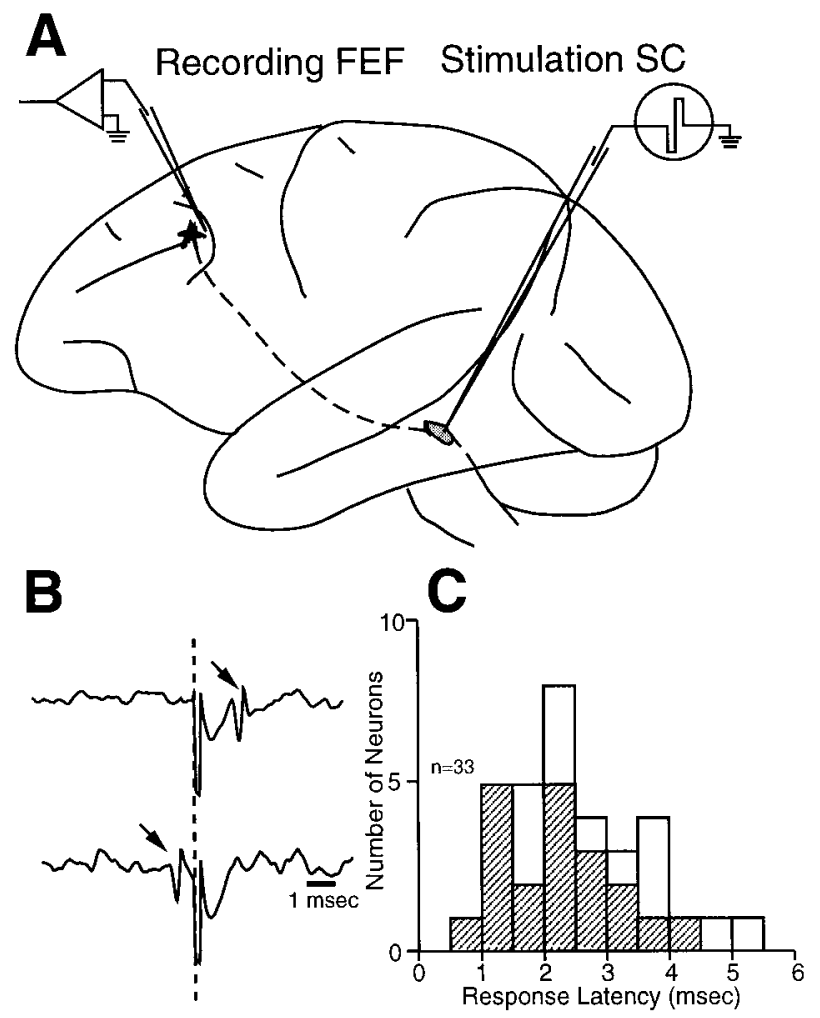

Figure 1. Experimental configuration and antidromic responses. $A$, Lateral view of a rhesus monkey brain illustrating single-neuron recording in the FEF and stimulation of the ipsilateral SC. B, Antidromic response of an FEF neuron (arrow, top trace) and its collision with a spontaneously generated action potential (arrow, bottom trace) that triggered microstimulation. The vertical dashed line indicates the time of SC stimulation. $C$, Histogram of antidromic latencies for 33 identified corticotectal neurons. Hatched bars indicate saccade-related neurons.

bility either at the position that yielded the optimal saccaderelated response of the neuron (response field) or at the mirror location on the opposite side of the horizontal and vertical meridians. The monkeys received a liquid reward if they looked within $500 \mathrm{msec}$ to the correct position and maintained fixation there for at least $200 \mathrm{msec}$. During the recording of each neuron, 15-20 trials of each of the eight conditions (pro/anti, gap/overlap, in/out response field) were presented in a pseudorandom order.

To dissociate stimulus-related from saccade-related responses, we also tested most of the neurons on a delayed visual and delayed memory saccade task (Munoz and Wurtz, 1995). Briefly, each trial started with the monkey fixating a FP in the center of the screen. A visual stimulus was then presented either in the center of the response field of the neuron or on the opposite side of the horizontal and vertical meridians. The stimulus either remained visible throughout the trial (delayed visual task) or disappeared after 100 msec (delayed memory task). The monkey was required to maintain central fixation on the FP for an additional period of 400-1000 msec, until the FP disappeared, which was the cue to look to the visible or memorized target. The monkey received a liquid reward if it looked to the visible or memorized target location within $500 \mathrm{msec}$ and maintained fixation there for at least $300 \mathrm{msec}$.

Data analysis. During off-line analysis, trials with reaction times $<80 \mathrm{msec}$ were excluded as anticipations and trials with reaction times $>500 \mathrm{msec}$ as no-response trials. For all analyses, 


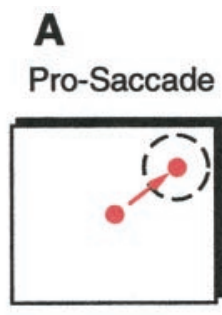

B
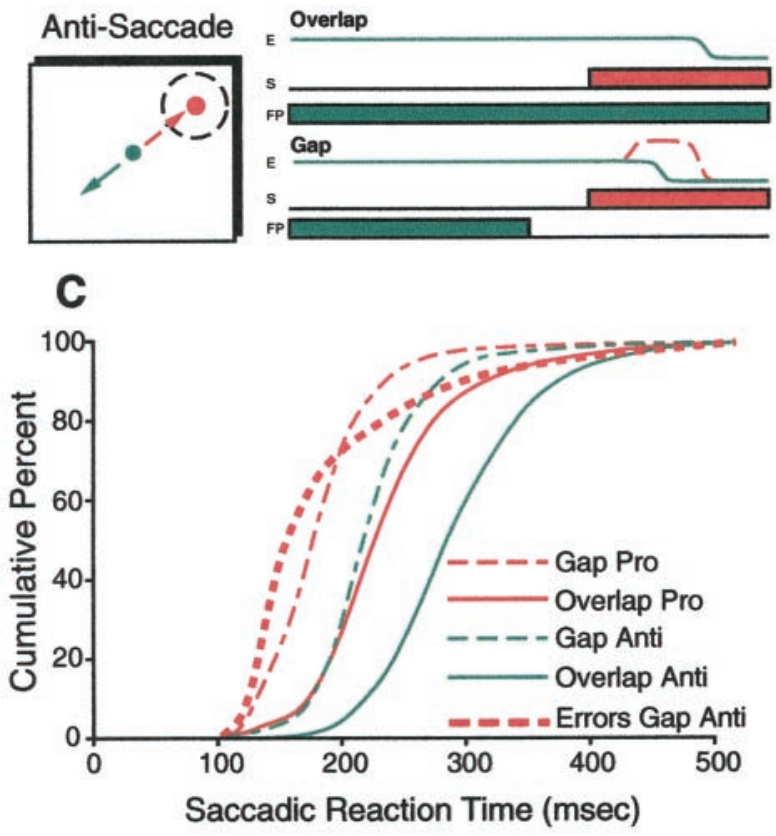

Figure 2. Spatial and temporal representation of the behavioral paradigm. $A, B$, The monkey was required to look at a central FP for 700-900 msec. A red FP signaled a pro-saccade trial, and a green FP signaled an anti-saccade trial. On half of the trials, the FP disappeared $200 \mathrm{msec}$ before the peripheral stimulus was presented (Gap condition). On the other half of the trials, the FP remained illuminated throughout the trial (Overlap condition). A red stimulus was then presented pseudorandomly and with equal probability either in the response field of the neuron (dashed circle) or at the mirror position. On pro-saccade trials $(A)$, the monkey was required to look toward the stimulus (red solid arrow), whereas he had to look to the mirror position (green solid arrow) on anti-saccade trials $(B)$. Monkeys sometimes generated incorrect responses in the gap anti-saccade condition (red dashed arrow). E, Eye position; $F P$, fixation point; $S$, stimulus. $C$, Cumulative distribution of SRTs of all pro-saccades (red) and anti-saccades (green) in the gap (dashed lines) and overlap conditions (solid lines) obtained while recording from neurons in the FEF. The thick dotted red line represents incorrect responses in the gap anti-saccade condition. The mean SRT $\pm \mathrm{SD}$ (and number of responses) in each condition was pro-gap, $164 \pm 130 \mathrm{msec}(n=$ 5303); pro-overlap, $239 \pm 142 \mathrm{msec}(n=5210)$; anti-gap, $205 \pm 111 \mathrm{msec}$ $(n=4455)$; anti-overlap, $279 \pm 122 \mathrm{msec}(n=4532)$; direction errors in the anti-gap, $179 \pm 233 \mathrm{msec}(n=1482)$.

only neurons with at least five trials for each condition were included. A Gaussian activation function (Richmond and Optican, 1987) with a SD of 20 msec was used to construct continuous spike density waveforms and to obtain the levels of neuronal activity with a binwidth of $1 \mathrm{msec}$. Smaller SDs (4 and $10 \mathrm{msec}$ ) did not change the overall shape of the activation waveform, but resulted in a higher scatter caused by the relatively low discharge rate of cortical neurons. For comparing the neuronal activity during the instruction period (visible fixation point: red, prosaccade; green, anti-saccade), we determined the mean activity during the period 400-200 msec before stimulus presentation for correct pro-saccade and anti-saccade trials. Gap and overlap trials were combined for this analysis. For comparing the neuronal prestimulus activity, we determined the mean activity in the period 40-50 msec after stimulus presentation. This period reflected the level of activation of the neuron before the visual signal arrives in the FEF $(>70 \mathrm{msec}$ for our sample; see also Schmolesky et al., 1998). For comparing stimulus-related responses, we determined the mean activity in the interval $\pm 5 \mathrm{msec}$ around the peak of neuronal activation in a time window from 70 to $140 \mathrm{msec}$ after stimulus appearance, and the prestimulus activation in the interval $40-50 \mathrm{msec}$ after stimulus presentation was subtracted as the baseline activity from this value. This analysis was performed on trials collected in the overlap condition only with the exclusion of all saccades with SRTs $<150 \mathrm{msec}$ to avoid a contamination of the stimulus-related response with saccaderelated activity. For comparing saccade-related responses, we determined the largest peak of activity in the interval from 20 msec before to $40 \mathrm{msec}$ after saccade initiation for each neuron in the overlap condition. Then, the average activity was measured in a $10 \mathrm{msec}$ interval extending from $5 \mathrm{msec}$ before to $5 \mathrm{msec}$ after the peak. For this analysis, only saccades that landed within a radius that deviated less than $\pm 25 \%$ of the optimal vector of the saccade were included. Comparisons were performed with a paired Student's $t$ test or, if a test of normal distribution failed (Kolmogorov-Smirnov test), with the nonparametric Wilcoxon signed-rank test.

Neuron classification. We used the classification scheme of Bruce and Goldberg (1985) and Segraves and Goldberg (1987) to classify FEF neurons based on their discharge. After isolating a single neuron in the FEF for recording, it was tested for a corticotectal projection with antidromic stimulation of the SC. We then recorded its activity in the combined pro-/anti-saccade task (Fig. 2). The delayed visual and memory saccade tasks were then used to dissociate stimulus-related and saccade-related responses. Only neurons that increased their discharge transiently for saccades into their response field were classified as saccade-related. If we could not maintain stable recording long enough to run the delayed visual and memory saccade tasks, we classified the neuron on the basis of its discharge behavior during the anti-saccade condition. Only neurons that increased their discharge transiently for anti-saccades in their response field were classified as saccaderelated. For all analyses, we only included saccade-related neurons that increased their discharge $>20$ spikes/sec for visually guided saccades. Of these saccade-related neurons, we classified neurons as visuomovement neurons if they also increased their discharge $>20$ spikes/sec after the appearance of a visual stimulus in their receptive field. Saccade-related neurons that increased their discharge $<20$ spikes/sec after the appearance of a visual stimulus were classified as movement neurons only.

\section{RESULTS}

\section{Behavior}

Figure $2 C$ shows the cumulative distribution of SRTs obtained from the two monkeys in the combined pro-/anti-saccade paradigm during experiments in which we recorded from FEF neurons. Consistent with our previous observations, anti-saccades had longer SRTs than pro-saccades, and saccades in the overlap condition had longer SRTs than saccades in the gap condition. Furthermore, anti-saccades in the gap condition had shorter SRTs than pro-saccades in the overlap condition. The shortest SRTs were observed for direction errors in the anti-saccade gap 

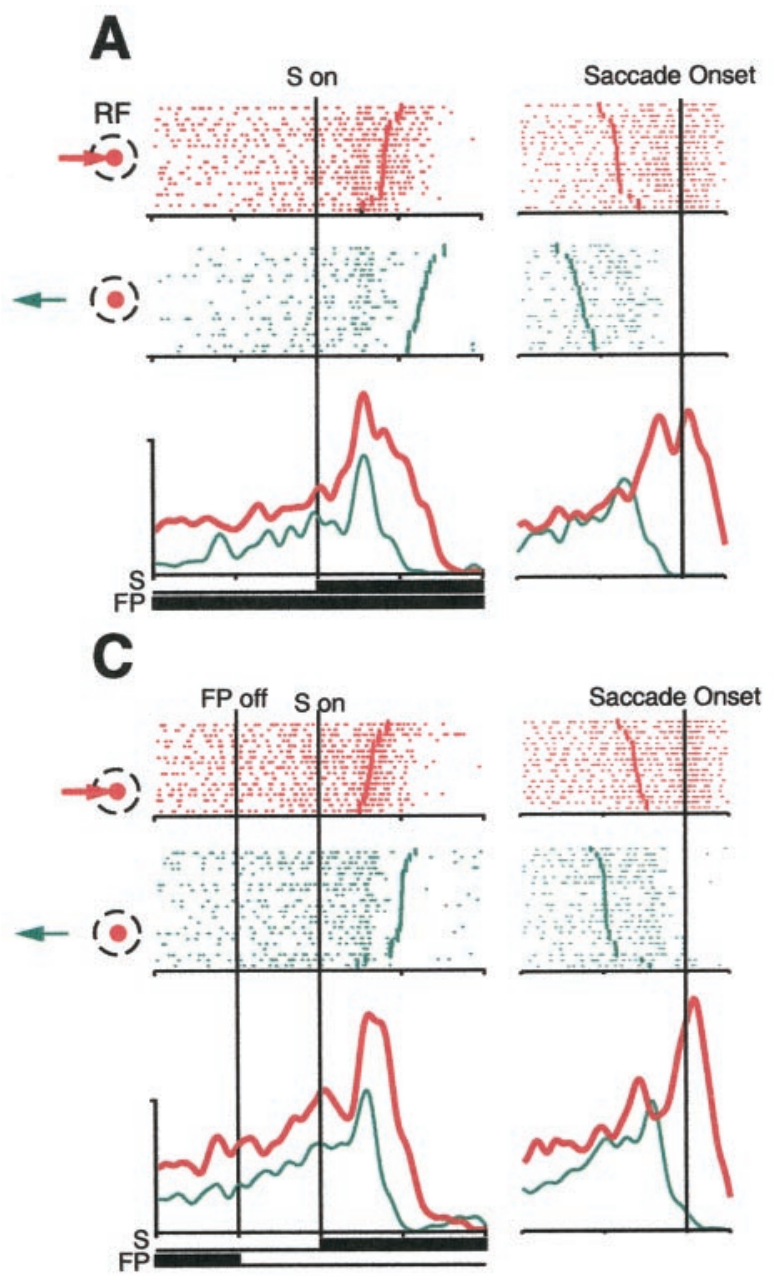

B
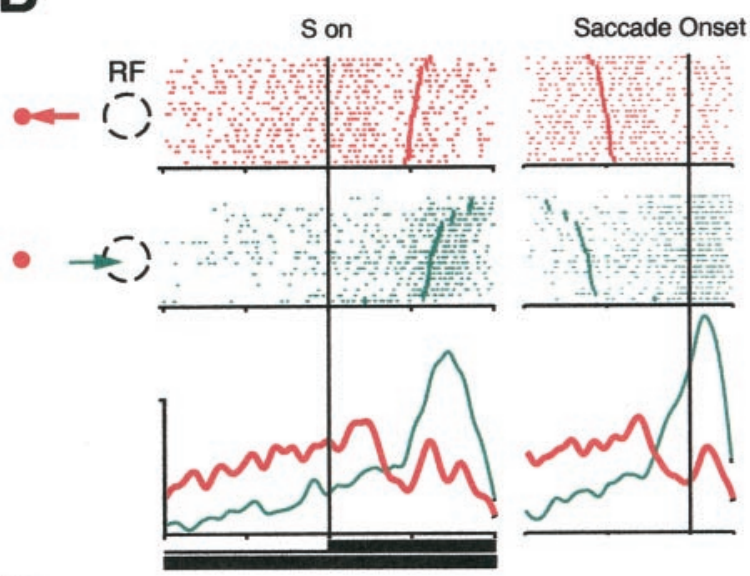

D
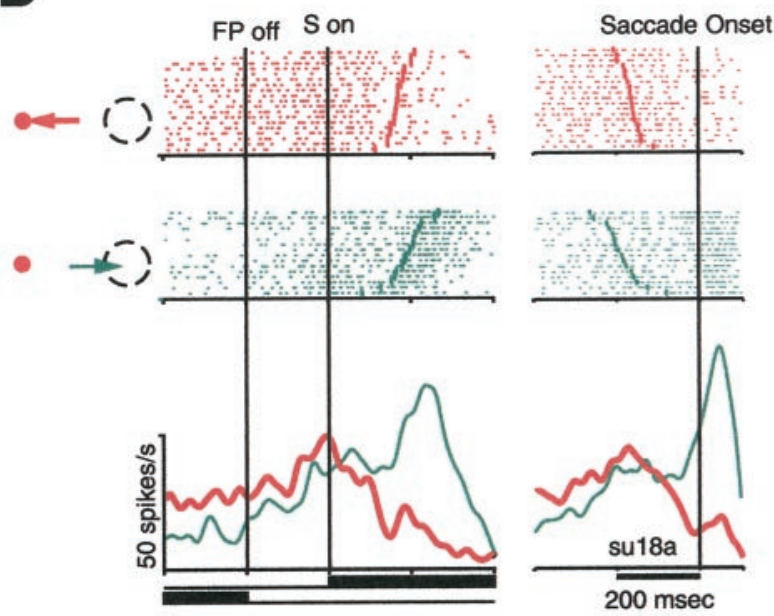

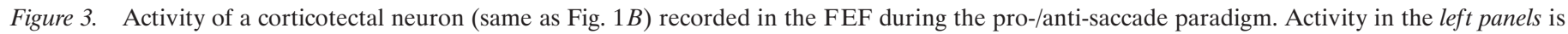

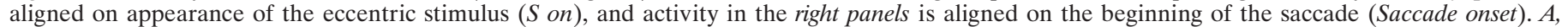

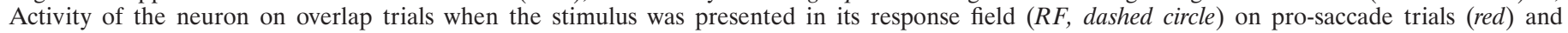

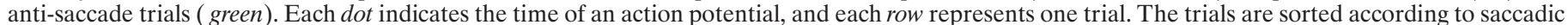

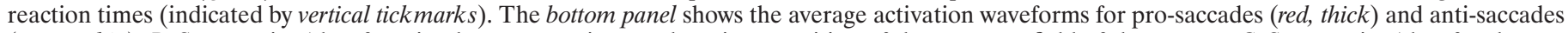

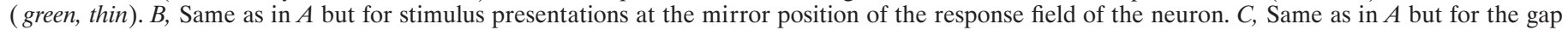

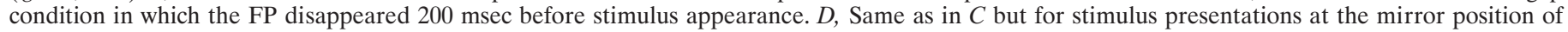
the response field of the neuron in the gap condition.

condition. Figure $2 C$ also illustrates the broad distribution of SRTs for all types of saccades.

\section{Identification of corticotectal neurons}

The antidromic identification of a corticotectal visuomovement neuron is shown in Figure $1 B$, and its activity in the combined pro-/anti-saccade task is illustrated in Figure 3. Stimulation of the $\mathrm{SC}$ led to activation of an action potential in the neuron after a fixed delay of $1.7 \mathrm{msec}$ (Fig. $1 \mathrm{~B}$, top trace). When the SC stimulation immediately followed an orthodromic action potential (Fig. $1 B$, bottom trace), the response to SC stimulation was annihilated, verifying that the response was caused by antidromic activation (Lipski, 1981). In the combined pro-/anti-saccade task, the neuron increased its discharge shortly after the visual stimulus appeared in its response field (Fig. 3A,C, left panels, all rasters). On prosaccade trials, the neuron then discharged for saccades into its response field, whereas the activity was suppressed before an anti-saccade was generated away from the response field (Fig. $3 A, C$, right panels, bottom rasters). The neuron also increased its discharge for all saccades into its response field (Fig. 3A,C, right panels, top rasters; $B, D$, right panels, bottom rasters). Therefore, the neuron was classified as a corticotectal visuomovement neuron. The peak in saccade-related discharge, however, was later for anti-saccades than for pro-saccades. This discharge pattern is similar to SC neurons (Everling et al., 1999). The neuron also had a lower activity during the instruction period before stimulus appearance on anti-saccade trials compared with pro-saccade trials (green traces below red traces). The neuron increased its activity during the gap period on pro-saccade and anti-saccade trials (Fig. 3C,D).

In a total of 85 experimental sessions, we recorded from 176 neurons in the FEF. Eighty neurons displayed saccade-related activity (32 visuomovement and 48 movement) and provided sufficient data for this report. In 25 of these sessions, the monkeys were implanted with stimulation electrodes inserted into the intermediate layers of the SC for antidromic identification. During these sessions, we identified 33 neurons as corticotectal (Fig. 
Table 1. Comparison of activity in pro-saccade versus anti-saccade trials

\begin{tabular}{|c|c|c|c|c|c|c|}
\hline \multirow[b]{2}{*}{$n$} & \multicolumn{2}{|c|}{ Activity (mean \pm SEM [range] in spikes/sec) } & \multicolumn{3}{|c|}{ Group statistics } & \multirow[b]{2}{*}{ Tes } \\
\hline & Pro-saccades & Anti-saccades & df & $t$ & $p$ & \\
\hline \multicolumn{7}{|c|}{ Instruction period } \\
\hline 80 & $9.4 \pm 0.8(0-33)$ & $7.4 \pm 0.8(0-40)$ & & & $<0.0001$ & $\mathrm{~W}$ \\
\hline$(18)$ & $(10 \pm 1.5[0-21])$ & $(7.1 \pm 1.1(0-19)$ & & & $(<0.01$ & $\mathrm{W})$ \\
\hline \multicolumn{7}{|c|}{ End of the gap period } \\
\hline 79 & $20.2 \pm 1.6(1-64)$ & $15.8 \pm 1.3(0-61)$ & & & $<0.0001$ & $\mathrm{~W}$ \\
\hline$(18)$ & $(15.7 \pm 3.0[1-46])$ & $(12.7 \pm 2.8[2-41])$ & $(17$ & 1.58 & 0.13 & $\mathrm{~T})$ \\
\hline \multicolumn{7}{|c|}{ Level of prestimulus activity } \\
\hline 32 & $13.4 \pm 2.2(0-53)$ & $9.9 \pm 2.0(0-55)$ & 31 & 3.74 & $<0.001$ & $\mathrm{~T}$ \\
\hline$(6)$ & $(16.8 \pm 5.5[3-37])$ & $(10.8 \pm 3.1[3-2-])$ & $(5$ & 2.16 & 0.08 & $\mathrm{~T})$ \\
\hline \multicolumn{7}{|c|}{ Magnitude of stimulus-related activity } \\
\hline 32 & $49.9 \pm 4.9(21-123)$ & $37.7 \pm 5.0(8-132)$ & 31 & 6.10 & $<0.0001$ & $\mathrm{~T}$ \\
\hline$(6)$ & $(37.8 \pm 5.8[22-63])$ & $(25.7 \pm 4.2[12-34])$ & $(5$ & 2.58 & $<0.05$ & $\mathrm{~T})$ \\
\hline \multicolumn{7}{|c|}{ Level of pre-saccade activity } \\
\hline 46 & $57.0 \pm 4.4(12-116)$ & $34.1 \pm 3.2(4-100)$ & 45 & 5.03 & $<0.0001$ & $\mathrm{~T}$ \\
\hline$(8)$ & $(40.0 \pm 4.6[21-54])$ & $(40.5 \pm 7.0[11-64])$ & & & $(0.74$ & $\mathrm{W})$ \\
\hline \multicolumn{7}{|c|}{ Magnitude of saccade-related activity } \\
\hline 46 & $82.4 \pm 8.2(28-284)$ & $53.5 \pm 5.1(7-167)$ & 45 & 4.83 & $<0.0001$ & $\mathrm{~T}$ \\
\hline$(8)$ & $(64.3 \pm 5.9[41-87])$ & $(64.3 \pm 10.2[26-101])$ & & & $(0.74$ & $\mathrm{W})$ \\
\hline
\end{tabular}

The bracketed values are from identified corticotectal neurons.

W, Wilcoxon signed rank test; T, Student's $t$ test.

1). Of these 33 neurons, $18(54 \%)$ neurons were identified as saccade-related (12 visuomovement and 6 movement neurons). The remainder comprised other classes of FEF neurons (Bruce and Goldberg, 1985). The distribution of antidromic latencies is illustrated in Figure $1 C$. The mean antidromic latency \pm SD for all 33 antidromic neurons was $2.49 \pm 1.08 \mathrm{msec}$ (range, 0.8-5.0 msec) and for the 18 saccade-related neurons (described in this report) it was $2.13 \pm 0.93 \mathrm{msec}$ (range, $0.8-4.0 \mathrm{msec}$ ). Antidromic neurons that did not fulfill our criteria for saccade-related neurons had slightly longer latencies $(2.93 \pm 1.12 \mathrm{msec}$; range, $1.2-5.0$ msec; unpaired $t$ test, $t=2.27$; df $=32 ; p=0.031)$. The range of values we report (Fig. 1C) is comparable to the antidromic latencies described previously for corticotectal neurons in the FEF (Segraves and Goldberg, 1987: mean, $2.25 \mathrm{msec}$, range, 1.2-6.0 msec; Sommer and Wurtz, 1998: mean, $2.1 \pm 1.5 \mathrm{msec}$, minimum, $0.7 \mathrm{msec})$.

To establish whether neural activity in the FEF reflected variations in preparatory set and influenced the ensuing behavioral performance, we performed correlations between FEF neural activity and behavioral responses and between FEF neural activity and task condition. In the subsequent sections, we contrast the discharge of all FEF saccade-related neurons in the pro-/antisaccade paradigm (1) during the instruction period before stimulus appearance, (2) during the gap period, (3) between prestimulus activity and SRT, (4) between prestimulus activity and express saccades, (5) between prestimulus activity and antisaccade errors, (6) in the magnitude of stimulus-related activity, and (7) in the magnitude of saccade-related activity. For each analysis, at least five responses were required in each category. Therefore, the number of neurons tested in each analysis varied. In each analysis we summarize the results for all saccade-related neurons (Table 1) and the subset of neurons antidromically activated from the SC (Table 1, bracketed values; Figs. 4, 5, 7-11, filled squares).

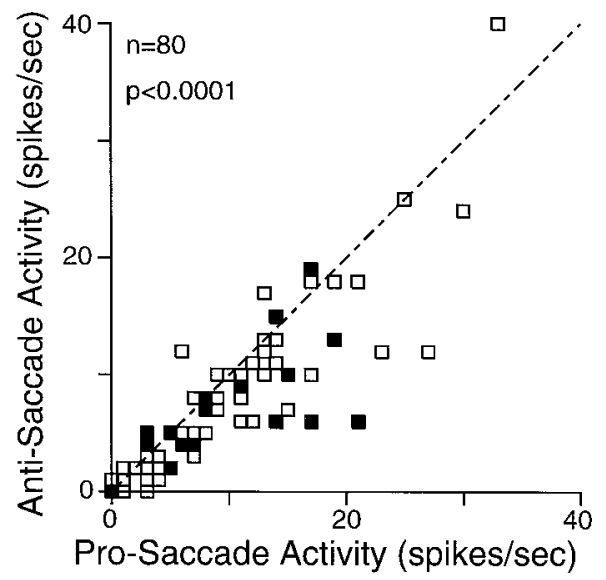

Figure 4. Activity during the instruction period. The mean discharge rate of individual neurons in the period 400-200 msec before stimulus presentation on pro-saccade trials is plotted against the mean activity on anti-saccade trials. Filled squares indicate antidromically activated corticotectal neurons. Dashed line is the unity line (slope, 1).

\section{Instruction period-related neuronal activity}

Monkeys were instructed by the color of the initial FP at the beginning of each trial, whether they were required to generate a pro-saccade or an anti-saccade after peripheral stimulus presentation (Fig. 2A,B). Therefore, if the activity of FEF neurons reflects preparatory set, neurons should show differential activation patterns between pro-saccade and anti-saccade trials during the instruction period (red FP, pro-saccade; green FP, antisaccade). We quantified the activity during the instruction period for the population of saccade-related neurons in the interval 200-400 msec before stimulus presentation (Table 1, Fig. 4). A lower activity on anti-saccade trials was found in the majority of neurons (51 of 80 , or $64 \%$ ). These differences were significant for 
Figure 5. Prestimulus activity on overlap and gap trials. $A$, Mean spike density on pro-saccade trials (thick lines) and antisaccade trials (thin lines) in the overlap (sol$i d$ lines) and gap (dashed lines) conditions. $B$, The mean discharge rate of individual neurons in the period $40-50 \mathrm{msec}$ after stimulus presentation ( $A$, shaded region) on overlap pro trials (mean, $11.7 \pm 1.1$ spikes/ $\mathrm{sec}$ ) is plotted against the mean activity on gap pro trials (mean, $19.8 \pm 1.6$ spikes $/ \mathrm{sec}$ ). Filled squares indicate antidromically activated neurons. Dashed line is the unity line (slope, 1). $C$, Same as in $B$ but for the comparison of anti-saccades between the gap (mean, $15.7 \pm 1.1 \mathrm{spikes} / \mathrm{sec}$ ) and overlap condition (mean, $9.0 \pm 1.4$ spikes/sec). $D$, Same as in $B$ but for the comparison between pro- and anti-saccades in the gap condition.
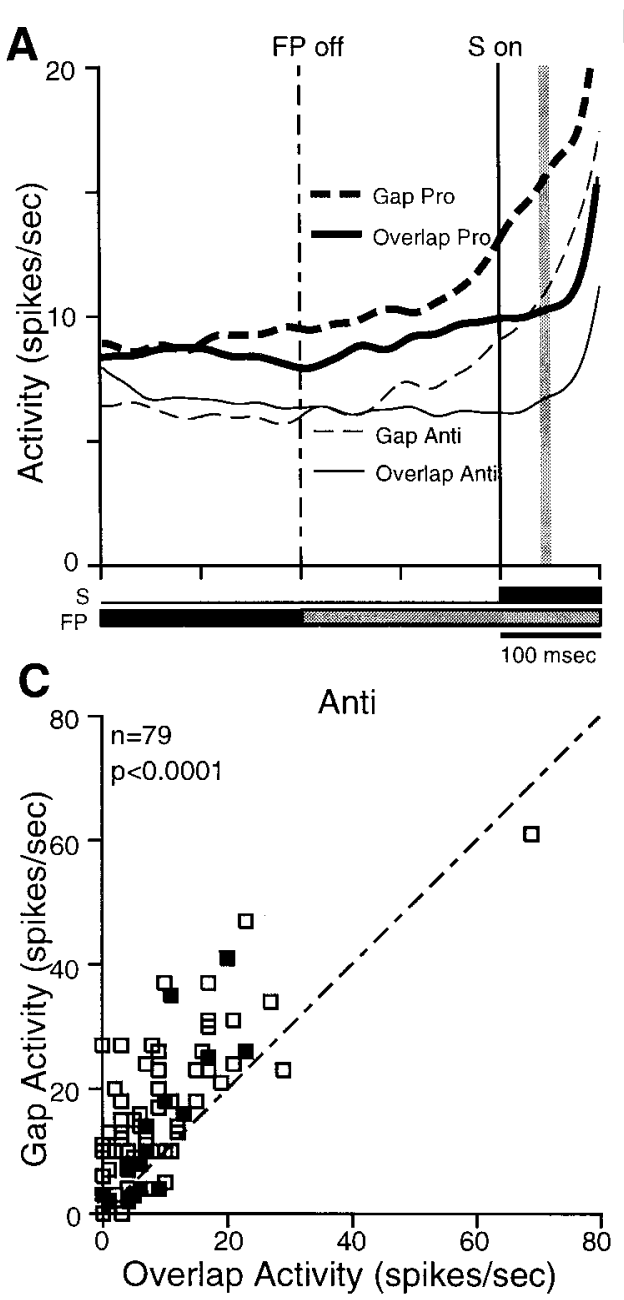

B
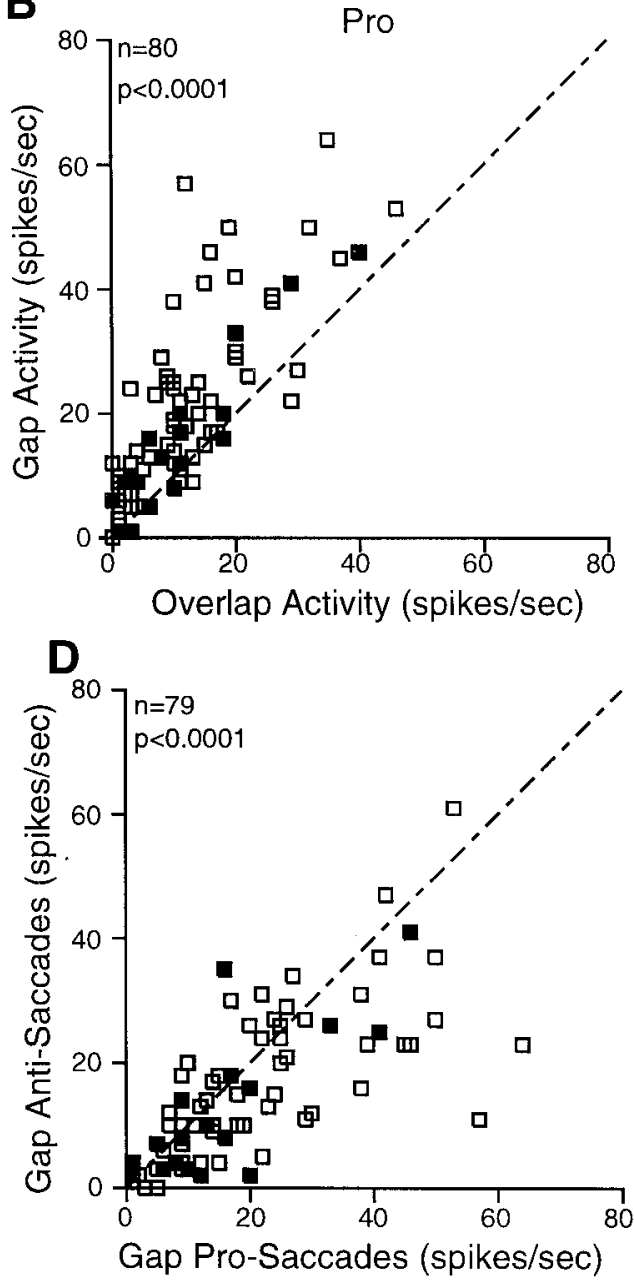

$31 \%$ (25 of 80 ) of the neurons $(t$ test, $p<0.05)$ and for the population. This finding revealed that FEF saccade-related neurons do indeed modulate their activity during the instruction period, before the stimulus is presented.

\section{Gap-related neuronal activity}

To examine whether the activity of FEF neurons represents a neuronal correlate for the reduction of SRTs in the gap saccade task (Saslow, 1967; Fischer and Boch, 1983; Forbes and Klein, 1996; Paré and Munoz, 1996), half of the trials in the paradigm included a gap of $200 \mathrm{msec}$ between FP disappearance and stimulus appearance. Consistent with a previous report (Dias and Bruce, 1994), we observed an increase in discharge during the gap period in the majority of FEF saccade-related neurons (68 of 80 , or $85 \%$ ). Figure $5 A$ illustrates the activity of the 80 neurons as it evolved in the time leading up to appearance of the eccentric stimulus. There was an increase in activity $\sim 100 \mathrm{msec}$ after FP disappearance on both pro-gap and anti-gap trials. Significant differences ( $t$ test, $p<0.05)$ between gap and overlap pro-saccade trials were obtained for $58 \%$ (46 of 80 ) of the neurons (Fig. $5 B$ ) and for the population (Wilcoxon signed rank test, $p<0.0001$ ). Increases in discharge during the gap period compared with the overlap task on anti-saccade trials were found in $77 \%$ (61 of 79) of the neurons (Fig. $5 C$ ). These differences were significant ( $t$ test, $p<0.05$ ) in $44 \%$ (35 of 79) of the neurons and for the population (Wilcoxon signed rank test, $p<0.0001$ ).
The level of neuronal activity at the end of the gap period was significantly different between pro-saccade trials and correct antisaccade trials (Table 1, Fig. 5A,D). A significantly higher level of prestimulus activity on pro-saccade trials was observed in $30 \%$ (24 of 79) of the neurons. However, five neurons FEF neurons were significantly more active at the end of the gap period for anti-saccades than for pro-saccades.

\section{Relationship between SRT and neuronal activity}

Neurons that modulate their discharges during the gap period could account for the reduction of SRTs in the gap task as observed previously in the SC (Dorris et al., 1997; Dorris and Munoz, 1998; Everling et al., 1999). To test this hypothesis for FEF neurons, we computed the trial-by-trial correlation coefficient (Pearson's product-moment correlation coefficient $r$ ) between the level of prestimulus activity in $10 \mathrm{msec}$ bins beginning from $200 \mathrm{msec}$ before to $100 \mathrm{msec}$ after stimulation presentation with SRT in the gap condition for pro-saccade and anti-saccade trials. For this analysis, we selected neurons that had significant differences in prestimulus activity between the gap condition and the overlap condition on pro-saccade trials and for which we obtained at least 10 trials in each condition. For pro-saccades and anti-saccades, the correlation coefficients between SRT and the level of neuronal activity contralateral to the subsequent saccade became more negative the closer the correlation window moved to the onset of visual responses $(>70 \mathrm{msec}$ ) (Fig. 6A). The 


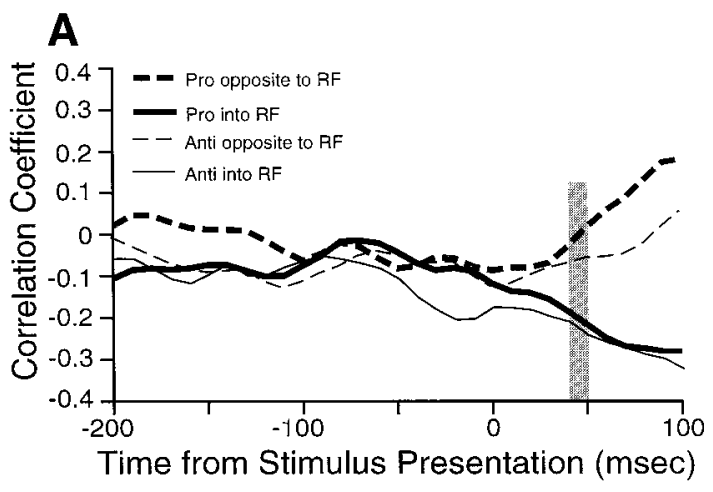

B
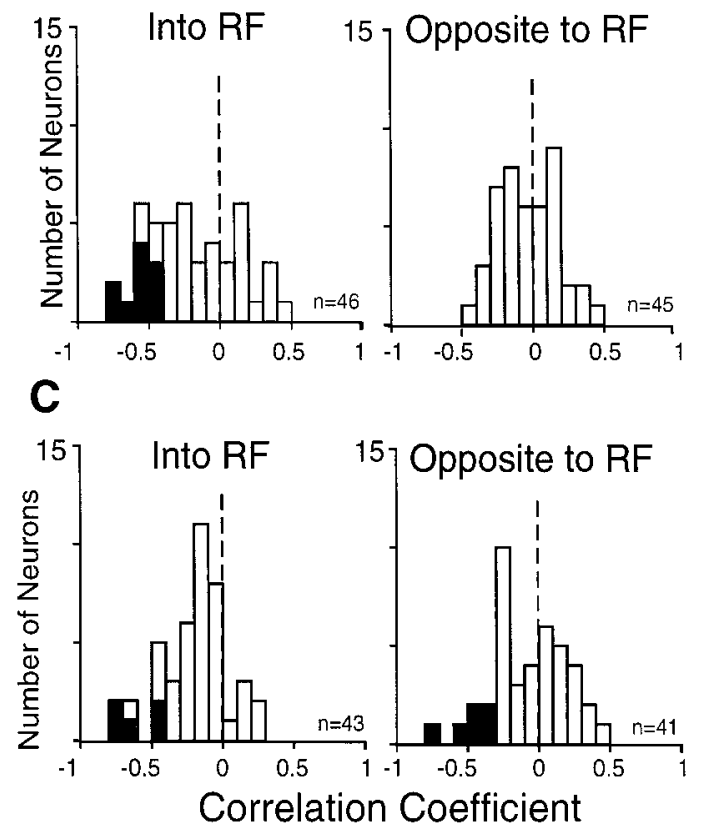

Figure 6. Relationship between neuronal activity and saccadic reaction times in the gap condition. A, Mean correlation coefficients between neuronal activity and saccadic reaction times in $10 \mathrm{msec}$ bins from 200 msec before to $100 \mathrm{msec}$ after stimulus presentation for pro-saccades (thick lines) and anti-saccades (thin lines) in the response field of the neuron (solid lines) and to opposite position (dashed lines). $B, C$, Distribution of correlation coefficients between the mean activity from 40-50 msec after stimulus presentation ( $A$, shaded area) and saccadic reaction time for pro-saccades and anti-saccades, respectively. The filled bars represent neurons with statistically significant correlations $(p<0.05)$.

distribution of correlation coefficients between prestimulus activity in the interval $40-50 \mathrm{msec}$ after stimulus appearance and SRT is shown in Figure 6, $B$ and $C$, respectively, for pro-saccades and anti-saccades. For pro-saccades, the mean correlation coefficient was -0.18 for saccades into the response field of the neuron (one sided $t$ test against $0, p=0.0003$ ) and -0.03 for saccades opposite to the response field of the neuron (one-sided $t$ test against $0, p=$ 0.33 ). For anti-saccades, the mean correlation coefficient was -0.20 for saccades into the response field of the neuron (one sided $t$ test against $0, p<0.0001$ ) and -0.07 for saccades opposite to the response field of the neuron (one sided $t$ test against $0, p=$ 0.12). This finding is consistent with the hypothesis that the prestimulus activity of FEF neurons reflects the monkey's preparatory state. The higher the level of prestimulus activity of a neuron is immediately before the arrival of the visual signal in the frontal eye field, the faster a saccade into the response field of the neuron will be initiated. Thus, the variability of SRTs is partly related to the variability of low-frequency prestimulus activity in FEF saccade-related neurons.

\section{Neuronal activity and express saccades}

We have shown that FEF saccade-related neurons increase their discharge during the gap period and that the level of pre-saccade neuronal activity correlated with SRT for contraversive saccades. A class of saccades with very short-latency SRTs that are favored by the gap condition, express saccades (Fischer and Boch, 1983), are thought to be generated by a direct route from the visual cortex via the intermediate layers of the SC to the saccade generator in the brainstem (Fischer, 1987; Schiller et al., 1987; Edelman and Keller 1996; Dorris et al., 1997). This hypothesis is based on the short latency of express saccades that approach the minimal afferent and efferent conduction times of this pathway (Carpenter, 1981) and on the experimental finding that lesions of the SC in monkey abolish express saccades, whereas lesions of the FEF in monkeys do not have long-term effects on the proportion of express saccades (Schiller et al., 1987).

To investigate the role of the FEF in express saccade generation, we separated pro-saccade trials in the gap condition into express saccade (SRTs, 80-125 msec) and regular saccade trials (SRTs, $\geq 125 \mathrm{msec}$ ). Figure $7 A$ illustrates the discharge of an FEF neuron during both express and regular saccade trials. The neuron had a higher discharge rate at the end of the gap period on express saccade trials than on regular saccade trials. It then discharged a saccade-related burst of action potentials for both express saccades and regular saccades. A higher prestimulus activity on express saccade trials was found for the population of FEF neurons (Fig. 7B, $C$; paired Student's $t$ test, df $=15 ; t=2.88$; $p=0.01)$. These findings demonstrate that a high level of activity in the FEF before stimulus presentation is associated with the generation of saccades with latencies in the range of express saccades.

Hanes and Schall (1996) have demonstrated that, in an oculomotor countermanding paradigm, saccades are elicited when the activity of saccade-related FEF neurons reaches a certain level of neuronal activity. This threshold trigger level remained constant for all saccadic latencies. Based on this finding, Hanes and Schall (1996) proposed a fixed saccade threshold for individual FEF neurons. To test this hypothesis for express saccades, we compared the pre-saccadic neuronal activity between express saccades and regular saccades. For this analysis, we determined the mean level of neuronal activity in the interval 20-10 msec before saccade initiation (Fig. 8A, hatched bar). This interval encompassed the activity that can influence saccade initiation (Hanes and Schall, 1996). Figure $8 B$ shows that the population of saccade-related neurons had a similar pre-saccade activity for express and regular saccades (paired Student's $t$ test, $\mathrm{df}=15 ; \mathrm{t}=$ 1.832; $p=0.087)$.

To address the question whether the motor discharge of FEF neurons is different for express and regular saccades, we also compared the saccade-related activity of both saccade types (Fig. $8 A$, shaded area). Figure $8 C$ shows that FEF neurons had the same motor discharge for both express and regular saccades (paired Student's $t$ test, df $=15 ; \mathrm{t}=0.31 ; p=0.76$ ). These results demonstrate that in intact primates the FEF is active before and during express saccades. 
Figure 7. Neural activity for express and regular saccades in the gap pro-saccade condition. $A$, Activity of a FEF neuron aligned on the presentation of the visual stimulus. Each dot indicates the time of an action potential relative to stimulus presentation, and each row represents one trial. The trials are sorted according to saccadic reaction times (indicated by vertical tickmarks). The bottom panel shows the average activation waveforms for express (thick) and regular (thin) saccades. $B$, Same as in $A$ but aligned on the beginning of the saccade. $C$, Mean spike density of the sample of FEF neurons on express saccade trials (thick line) and regular saccade trials (thin line) for saccades into the response field of the neurons. $D$, Activity levels in the time $40-50 \mathrm{msec}$ after stimulus presentation $(B$, shaded area) are plotted before express saccades (mean, $30.6 \pm 5.7$ spikes/sec) against the activity levels before regular saccades (mean, $20.8 \pm 3.9$ spikes $/ \mathrm{sec}$ ). The oblique dashed line represents the unity line (slope, 1). Filled squares indicate antidromically activated neurons.
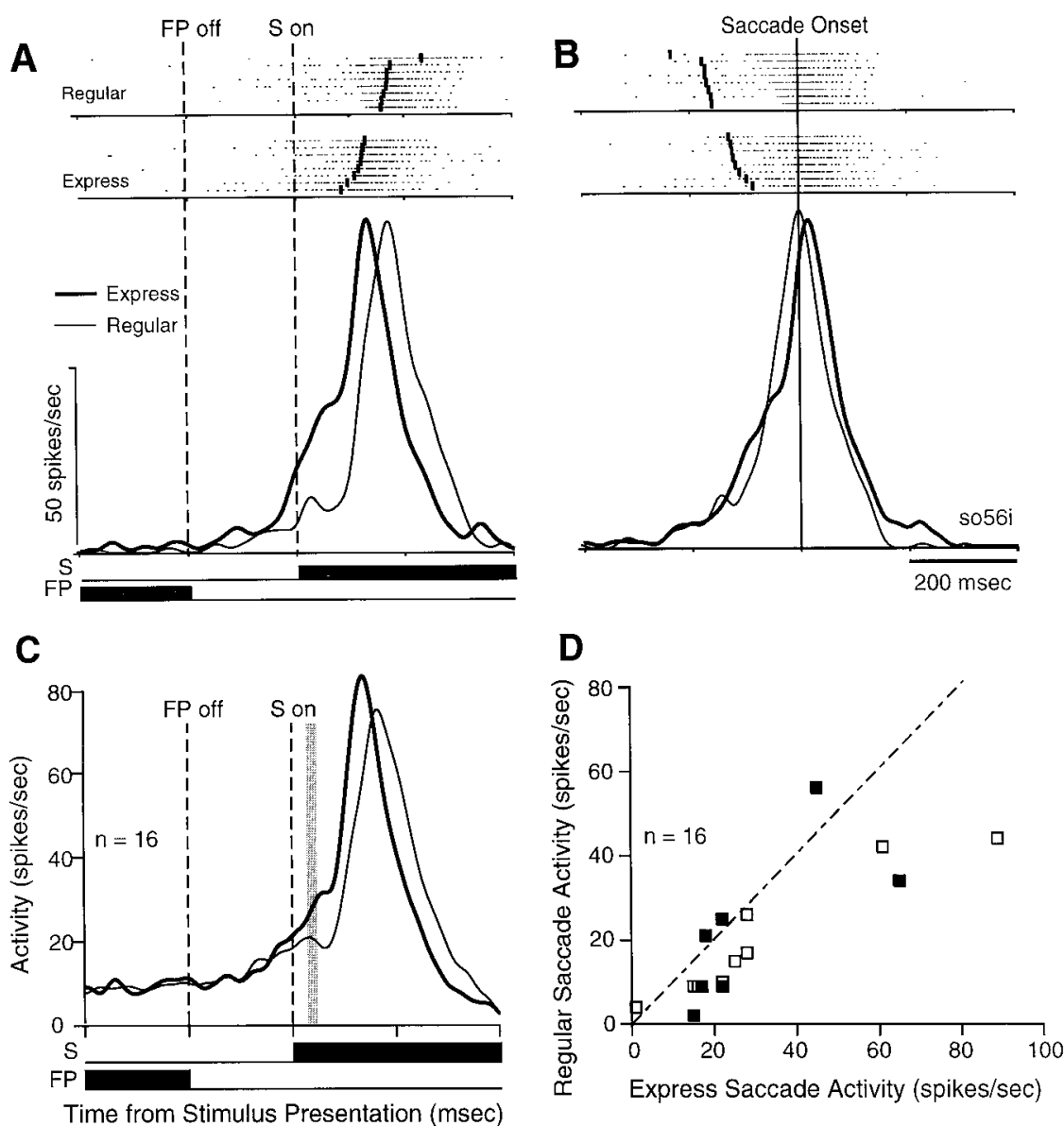

\section{Anti-saccade errors}

Humans and monkeys sometimes fail to suppress a reflexive saccade toward the stimulus in the gap condition when instructed to generate an anti-saccade (Everling et al., 1998a; Fischer and Weber, 1992; Munoz et al., 1998). These errors are especially high in young children (Munoz et al., 1998) and certain neurological or psychiatric disorders that involve in the frontal cortex and/or basal ganglia (for review, see Everling and Fischer, 1998). To determine whether neural processes in the FEF could account for performance in the anti-saccade task, we measured the activity level of neurons at the end of the gap period in the gap antisaccade task and compared between correct trials and error trials. For this analysis, we measured the level of neuronal activity in the period 40-50 msec after stimulus presentation in those neurons with a least five correct and five incorrect gap anti-saccade trials (35 neurons for stimulus presentations into the response field and 17 neurons for stimulus presentations at the mirror position). Figure $9 A$ shows the activity of an identified corticotectal neuron for gap anti-saccade trials in which the stimulus was presented in the response field of a neuron. The neuron increased its discharge during the gap period on correct trials and error trials, however, the activity was significantly higher on error trials ( $t$ test, $p<$ $0.05)$. We could confirm this observation for the population of FEF neurons (Fig. 9B, $C ; t$ test, $p=0.0002$ ). The neuron then displayed an increase in discharge that was higher for error trials. The same observation was made for the population of FEF neurons (Fig. 9B,C). The magnitude of this discharge on error trials was lower when the activity was aligned on saccade onset (data not shown). This finding indicates that this activity is primarily stimulus-related. No differences in the level of prestimulus activity were found between correct and error trials when the stimulus was presented at the mirror position of the response field of the neuron (Fig. 9D,E; Wilcoxon signed rank test, $p=0.31$ ). Thus, a high level of prestimulus activity of FEF neurons at the location where the visual stimulus was represented was associated with the generation of a reflexive saccade toward the stimulus (error) in the anti-saccade task.

\section{Stimulus-related neuronal activity}

Visuomovement neurons in the FEF increase their discharge after the presentation of a visual stimulus in their response field (Bruce and Goldberg, 1985; Thompson et al., 1996). The magnitude of this visual response is greater in a saccade task in which the stimulus is the target for a saccade compared with a fixation task in which the animal must maintain fixation (Wurtz and Mohler, 1976; Goldberg and Bushnell, 1981; Thompson et al., 1997). No enhancement of the stimulus-related activity was found when a saccade was made away from the response field of a neuron (Goldberg and Bushnell, 1981). In the anti-saccade task, the stimulus acts as both a distractor that can trigger an incorrect pro-saccade and as a landmark for the anti-saccade. To determine the effect of these task demands on the stimulus-related activity of visuomovement neurons, we compared the magnitude of the stimulus-related response between pro-saccade trials and antisaccade trials. All visuomovement neurons exhibited a stimulusrelated response only when the stimulus was presented in their response field, independent of the direction of the subsequent saccade (Fig. $3 A, C$ ). Figure $10 A$ shows the activity for the pop- 

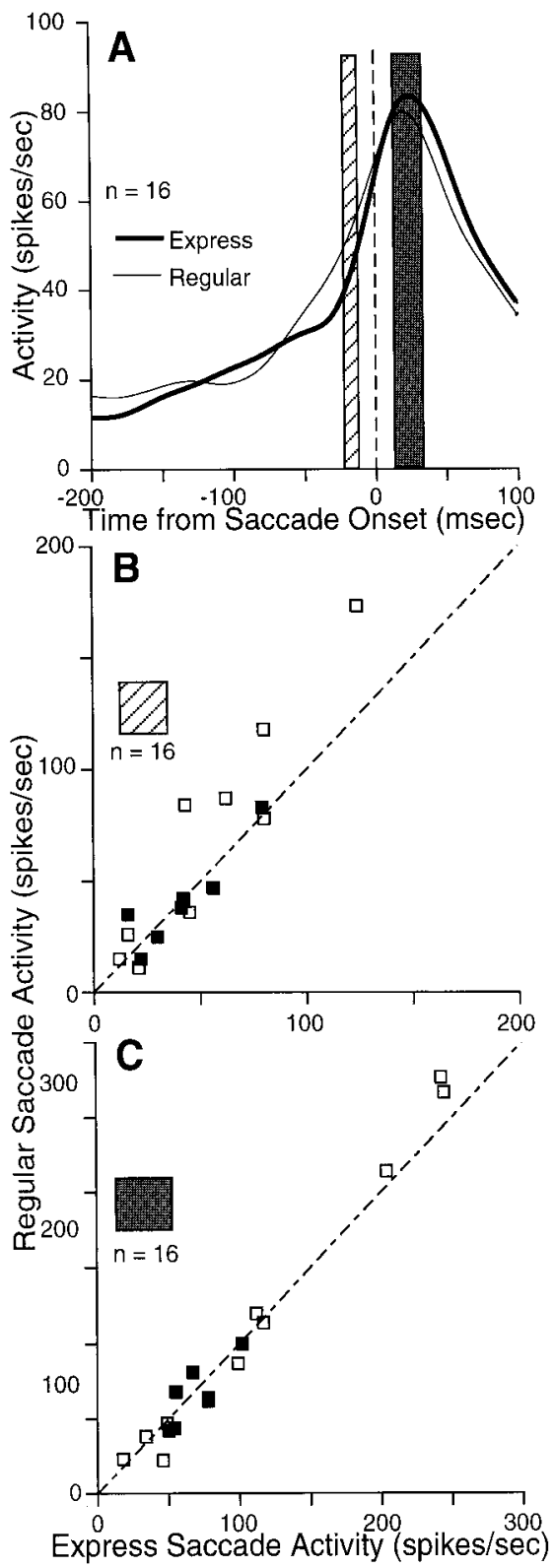

Figure 8. Comparison of saccade-related activity on express and regular saccade trials. $A$, Mean spike density of the sample of neurons on express saccade trials (thick line) and regular saccade trials (thin line) for saccades into the response field of the neurons. $B$, The pre-saccade activity in the interval $20-10 \mathrm{msec}$ before saccade onset ( $A$, hatched area) of individual neurons on express saccade trials (mean, $48.0 \pm 7.7 \mathrm{spikes} / \mathrm{sec}$ ) is plotted against the pre-saccade activity on regular saccade trials (mean, $56.8 \pm$ 10.9 spikes/sec). The oblique dashed line represents the unity line (slope, 1). Filled squares indicate antidromically activated neurons. $C$, The saccade activity ( $A$, shaded area) of individual neurons on express saccade trials (mean, $97.1 \pm 16.9$ spikes/sec) is plotted against the saccade activity on regular saccade trials (mean, $98.2 \pm 19.4$ spikes/sec).

ulation of saccade-related neurons with visual responses. Many neurons (19 of 32, or $60 \%$ ) had already a lower prestimulus activity on anti-saccade trials compared with pro-saccade trials (Table 1, Fig. 10B). This difference was significant for the population of FEF neurons. Therefore, we subtracted the prestimulus activity from the stimulus-related activity for the analysis of the magnitude of the stimulus-related response. Despite the identical properties of the stimulus, the majority of visuomovement neu- rons (28 of 32, or $87 \%$ ) had reduced visual responses on antisaccade trials (Table 1, Fig. 10A,C). These differences were significant in $52 \%$ (20 of 32) of the neurons and for the population. Thus, the reduced visual response of FEF neurons on anti-saccade trials is the result of both a reduced level of prestimulus activity and a reduced stimulus-related activity.

\section{Saccade-related neuronal activity}

Saccade-related neurons in the FEF increased their discharge for both pro-saccades and anti-saccades (Fig. 3). A comparison of the levels of pre-saccade activity before saccade initiation (Table 1, Fig. $11 A, B$ ) shows that FEF neurons had a lower pre-saccade activity before anti-saccades compared with pro-saccades. This finding indicates that, among individual neurons, there may be different saccade thresholds for pro- and anti-saccades.

To determine the role of FEF neurons in anti-saccade generation, we compared the magnitude of the saccade-related activity of the sample of neurons for pro-saccades and anti-saccades (Fig. $11 A, C)$. The population of saccade neurons in the FEF had a lower saccade-related activity for anti-saccades compared with pro-saccades (Table 1). However, a subset of neurons (11 of 46, or $24 \%$ ), exhibited slightly higher discharges for anti-saccades than for pro-saccades.

\section{DISCUSSION}

This study is the first to provide evidence that the direct descending pathway from the FEF to the SC carries set-related activity for saccades. Many saccade-related FEF neurons increased their activity significantly during the gap period, they had higher levels of prestimulus neuronal activity before express saccades compared with regular saccades, they had higher levels of prestimulus neuronal activity on anti-saccade trials when monkeys made errors, and they had significantly lower discharges during the instruction period, the gap period, and reduced visual responses on anti-saccade trials compared with pro-saccade trials. These correlations between neuronal activity and behavior are similar but weaker to those observed previously in SC neurons (Dorris et al., 1997; Everling et al., 1998a, 1999). The similar discharge pattern of SC and FEF neurons suggests that the preparatory set-related activity in SC neurons on pro-saccade and anti-saccade trials is mediated, at least in part, by direct descending projections from the FEF to the SC (Segraves and Goldberg, 1987).

\section{Prestimulus activity and SRTs}

The results described here demonstrate that the level of FEF neuronal activity immediately before stimulus presentation influences the reaction time of contralateral saccadic eye movements. The higher the activity, the shorter the subsequent SRT. Negative correlations between the level of prestimulus activity of single neurons and reaction times have been found for saccades in the SC (Dorris et al., 1997; Dorris and Munoz, 1998; Everling et al., 1999) and for limb movements in the primary motor cortex (Lecas et al., 1986; Riehle and Requin, 1993). Event-related potentials in humans have also shown differences in the prestimulus activation between fast and slow responses (Gratton et al., 1988; Everling et al., 1998b). In an oculomotor countermanding task, Hanes and Schall (1996) did not find significant differences in the level of prestimulus activity between saccades with short and long SRTs in FEF neurons. Instead, these authors reported that the stochastic growth rate of the activity of individual neurons toward a fixed threshold correlated with SRTs. It should however be noted that a byproduct of the countermanding task 
A

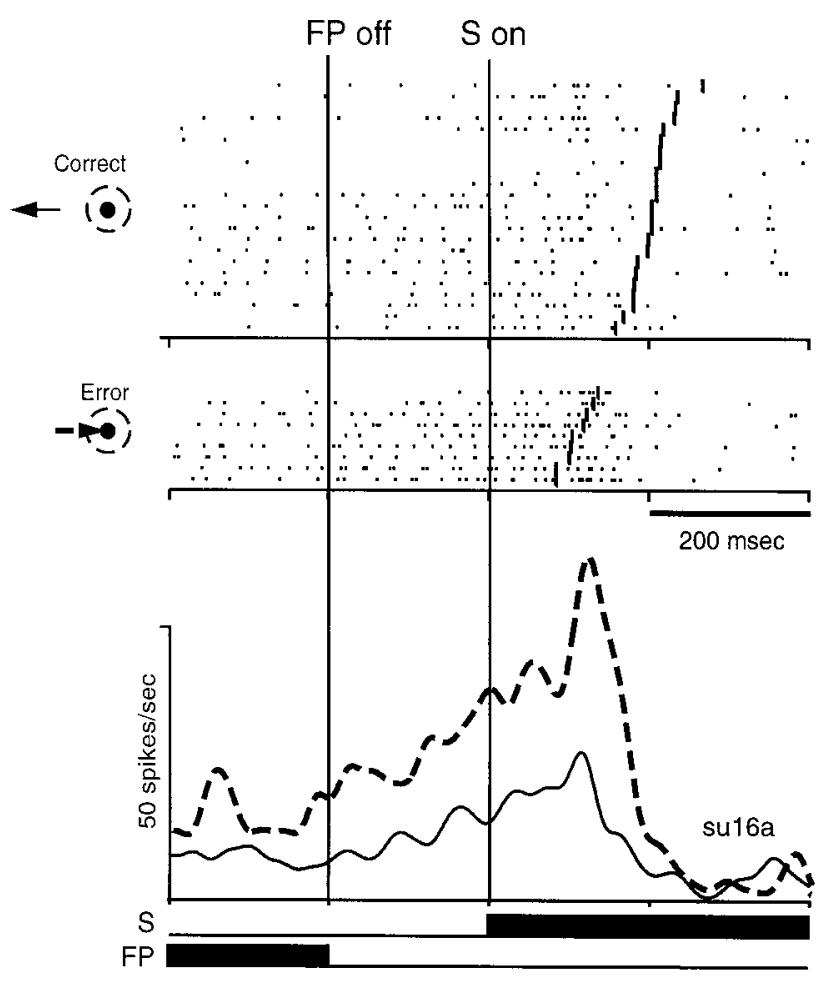

B
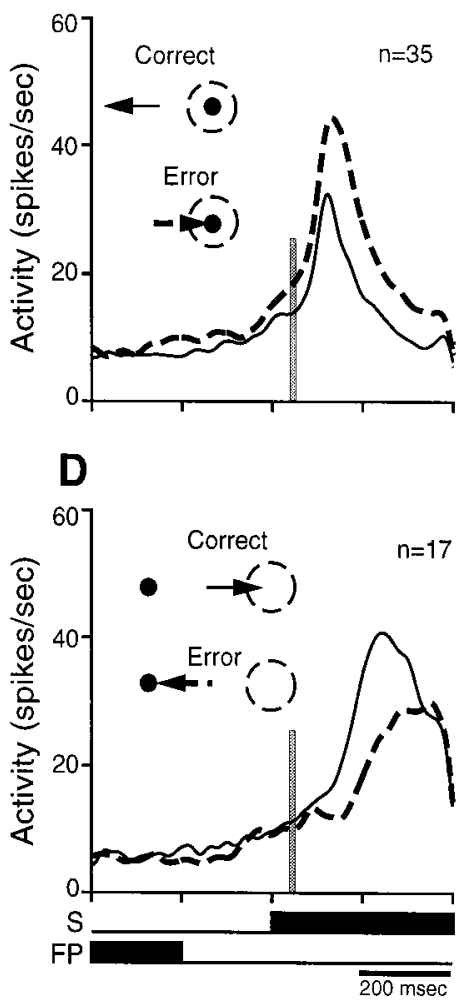

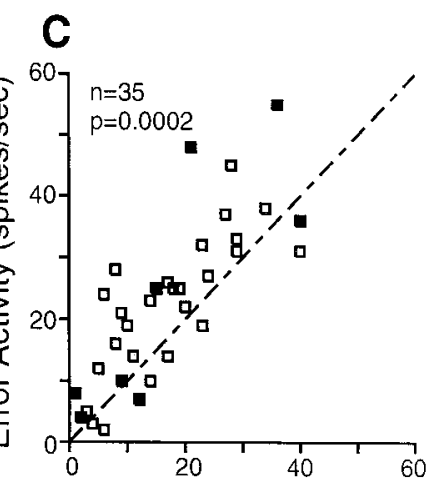

E

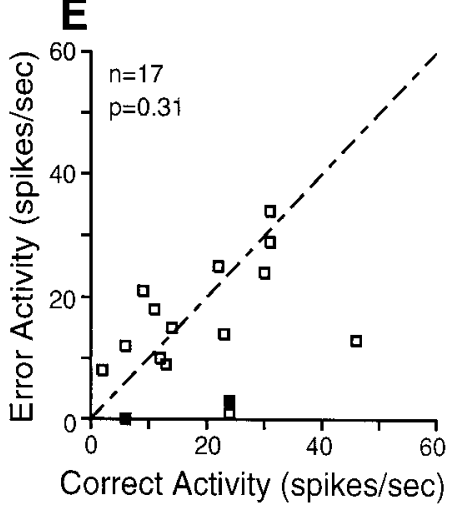

Figure 9. Activity on correct and error anti-saccade trials. A, Activity of an antidromically activated corticotectal neuron on correct trials (solid line) and error trials (dashed line) for stimulus presentations in the response field of the neuron (dashed circle). B, Mean spike density of the sample of FEF neurons on correct trials (thin solid line) and error trials (thick dashed line) for stimulus presentations into the response field of the neurons. $C$, Activity levels in the time $40-50 \mathrm{msec}$ after stimulus presentation (B, shaded area) are plotted before correct anti-saccades (mean, $16.7 \pm 1.9 \mathrm{spikes} / \mathrm{sec})$ against the activity levels before errors (mean, $22.4 \pm 2.3 \mathrm{spikes} / \mathrm{sec}$ ). The oblique dashed line represents the unity line (slope, 1). Filled squares indicate antidromically activated neurons. $D$, Same as in $C$ but for correct anti-saccades (mean, $18.2 \pm 2.9$ spikes/sec) and errors (mean, $13.8 \pm 2.5$ spikes/sec) for stimulus presentations at the mirror position.

used by Hanes and Schall (1996) is that SRTs were always $>200$ msec. Although we have not explicitly investigated this hypothesis, our finding of similar levels of presaccadic activity between express and regular pro-saccades does support the fixed-threshold hypothesis for FEF neurons for short-latency $(<200 \mathrm{msec})$ responses. It is quite likely that prestimulus activity plays an important role in dictating SRT for short-latency responses typical in the gap condition, whereas poststimulus activation is more important in determining SRT for the longer-latency responses obtained in an oculomotor countermanding task.

\section{Role of the FEF in the generation of express saccades}

Previous studies have demonstrated that monkeys can still generate express saccades after FEF lesions, whereas lesions of the SC abolish express saccades (Schiller et al., 1987). This observation suggested that FEF activation is not required for express saccade generation. In fact, it has been proposed that in humans express saccade generation may be facilitated after FEF lesions (Guitton et al., 1985). This hypothesis was supported by the finding that humans with lesions of the frontal cortex that included the FEF, showed an increased percentage of express saccades in a gap saccade task (Braun et al., 1992). A later study, however, observed the opposite saccade behavior in humans with lesions restricted to the FEF (Rivaud et al., 1994). The authors reported a bilateral increase in SRTs in the overlap task and a decreased number of express saccades in a gap saccade task in the patients with FEF lesions.
We observed that saccade-related neurons in the FEF had a higher prestimulus activity before express saccades compared to regular saccades (Fig. 7). Moreover, we found that FEF neurons were active during both express- and regular-latency saccades (Figs. 7, 8). How can the discrepancy between these findings and the finding of a clear lack of any effect of FEF lesions on the occurrence of express saccades (Schiller et al., 1987) be explained? We have suggested here that the similar discharge pattern of FEF and SC neurons on pro- and anti-saccade trials is partly the result of a descending projection from the FEF to SC (Segraves and Goldberg, 1987). However, the ascending disynaptic connection between the SC and the FEF via the mediodorsal thalamus (Lynch et al., 1994) leaves open the possibility that the differential activity of FEF neurons before express and regular saccades may in fact be driven at least in part by the SC. By examining the activity of FEF neurons that were likely to receive inputs from the SC, Sommer and Wurtz (1998) recently suggested that the SC sends visual-related and saccade-related activity to the FEF. If this hypothesis is true, then it is possible that the saccade-related activity of FEF neurons for express saccades may reflect the saccade-related activity in the SC for express saccades (Edelman and Keller, 1996; Dorris et al., 1997).

It has been hypothesized that in the case of an express saccade, the visual stimulus is capable of directly eliciting a saccade if saccade neurons in the SC have already a high prestimulus activity at the time of stimulus presentation (Sommer, 1994; Edelman 

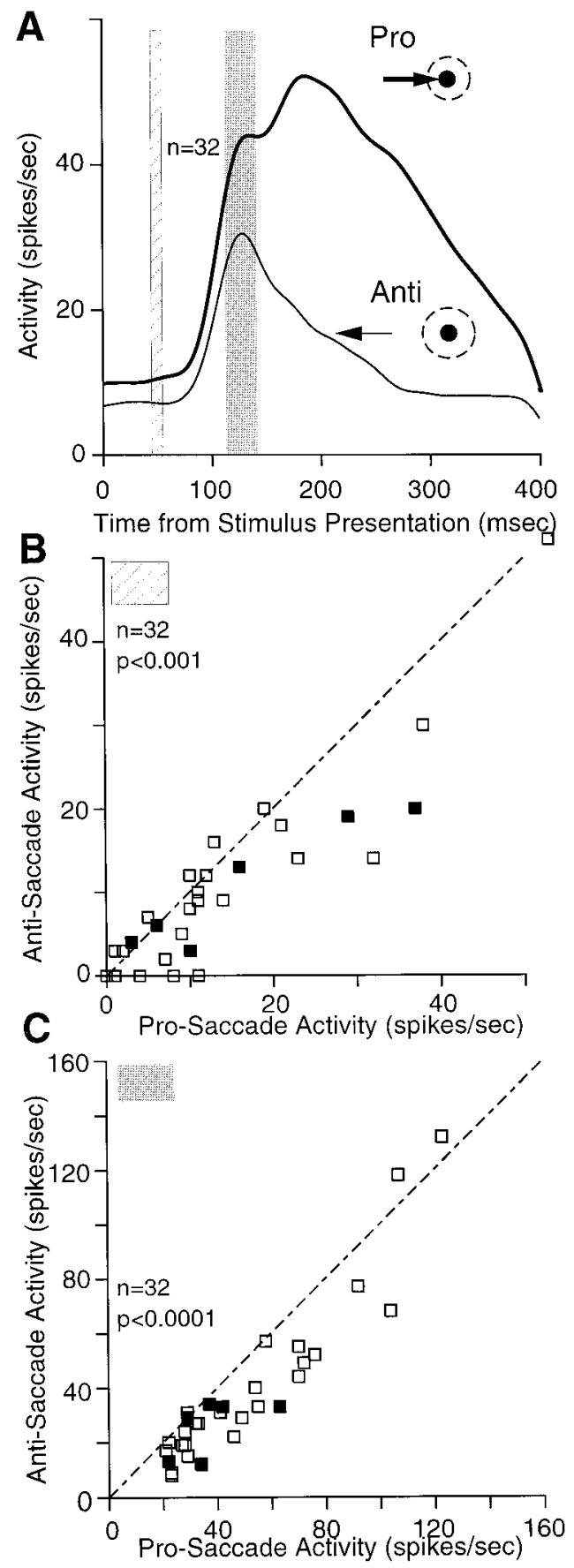

Figure 10. Stimulus-related activity. A, Mean spike density of the sample of visuomovement neurons on pro-saccade trials (thick line) and antisaccade trials (thin line) for stimulus presentations into the response field of the neurons. $B$, The prestimulus activity ( $A$, hatched areas) of individual neurons on pro-saccade trials is plotted against the prestimulusrelated activity on anti-saccade trials. $C$, The stimulus-related activity $(A$, shaded area) of individual neurons on pro-saccade trials is plotted against the stimulus-related activity on anti-saccade trials after subtracting the prestimulus level of activity ( $A$, hatched area). The oblique dashed lines represent the unity line (slope, 1). Filled squares indicate antidromically activated neurons.

and Keller, 1996; Dorris et al., 1997). In this case, the visual burst of these neurons can pass a certain saccade threshold, and it becomes functionally transformed into a motor burst. Although FEF lesions have no long-term effect on express saccade gener-
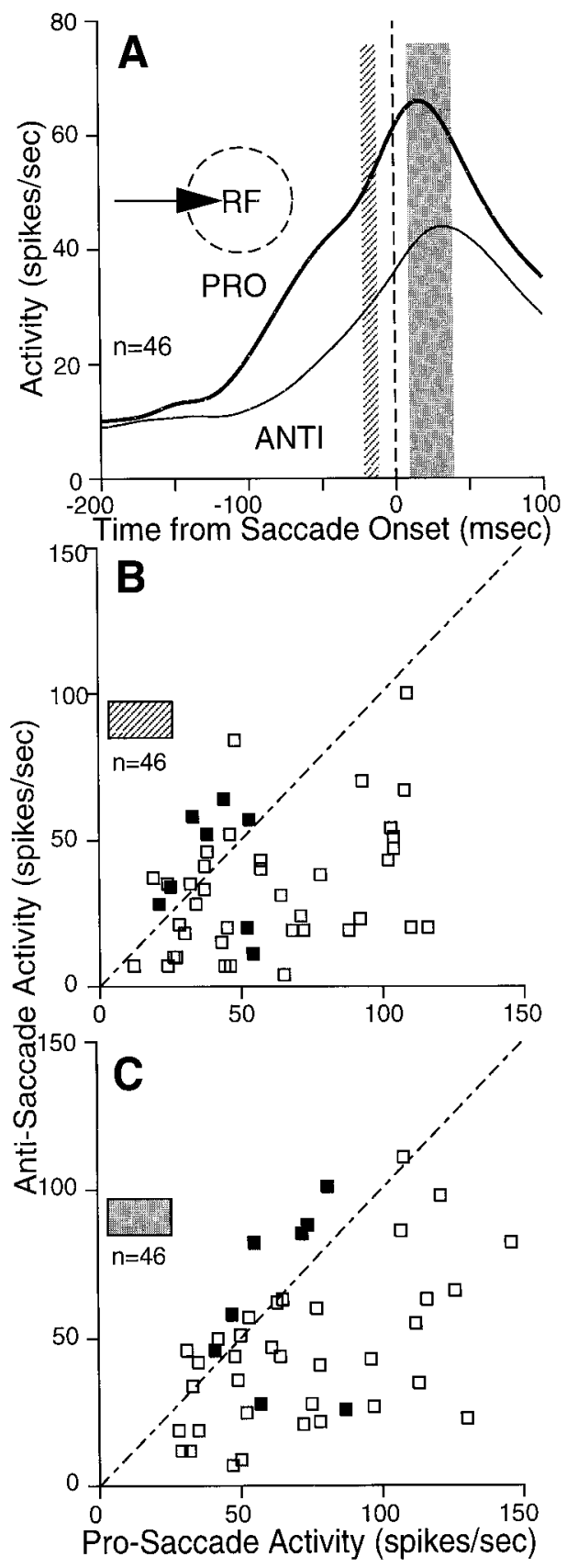

Figure 11. Saccade-related activity. $A$, Mean spike density of the sample of neurons on pro-saccade trials (thick line) and anti-saccade trials (thin line) for saccades into the response field of the neurons. $B$, The presaccade activity in the interval $20-10 \mathrm{msec}$ before saccade onset $(A$, hatched area) of individual neurons on pro-saccade trials is plotted against the pre-saccade activity on anti-saccade. The oblique dashed line represents the unity line (slope, 1). Filled squares indicate antidromically activated neurons. $C$, The saccade activity $(A$, shaded area) of individual neurons on pro-saccade trials is plotted against the saccade activity on anti-saccade trials.

ation, we hypothesize that the prestimulus activity in the FEF in intact monkeys participates in the generation of express saccades by increasing the excitation of SC neurons. The absence of longterm effects of FEF lesions on express saccade generation may result from post-lesion-induced neural plasticity that increases the excitability of SC neurons to compensate for the reduced cortical excitation. 


\section{Preparatory set for anti-saccades}

Primates are not constrained to react to sensory stimuli with reflexive movements, but rather they can acquire almost arbitrary stimulus-response associations (Wise et al., 1996a). The prefrontal cortex is thought be essential for the formations of these arbitrary associations (Passingham, 1993; Wise et al., 1996b). Several neurophysiological studies have shown that the activity of neurons in the frontal cortex reflects the formation of stimulusresponse associations (Chen and Wise 1995a,b, 1996; Assad et al., 1998). Lesions of the prefrontal cortex, however, do not only lead to difficulties in learning new associations, but also result in an inability to suppress inappropriate behavior (Fuster, 1991). This becomes evident in the anti-saccade task in which patients with damage to the prefrontal cortex often fail to suppress a reflexive saccade toward the stimulus before generating the anti-saccade (Guitton et al., 1985; Pierrot-Deseilligny et al., 1991).

The results of this study provide insights into how this executive control of the frontal cortex is expressed. The finding that saccade-related FEF neurons have lower discharges during fixation of the instruction cue on anti-saccade trials than on prosaccade trials seems to reflect a neuronal correlate for different preparatory sets necessary for the different task requirements. The finding of a decreased prestimulus activity in FEF neurons on anti-saccade trials seems to support the hypothesis that the correct performance of this task is dependent on a top-down control of the SC. Indeed, it has been shown that reflexive saccades (errors) in the anti-saccade task were preceded by a high prestimulus activity in a subset of SC saccade neurons and that they were associated with a vigorous burst of action potentials in response to stimulus presentation (Everling et al., 1998a). Therefore, to avoid reflexive unwanted saccades in the anti-saccade task, the activity of saccade neurons in the SC must be reduced until the motor signal for the anti-saccade is generated, which can only occur after stimulus presentation. The present results suggest that the brain may accomplish this task at least in part by reducing the excitatory drive from saccade-related FEF neurons to the SC during anti-saccade trials. We have shown recently that not only saccade-related neurons in the SC have a lower discharge during the instruction period but that fixation neurons in the SC have a higher discharge on anti-saccade trials compared with pro-saccade trials (Everling et al., 1999). It remains to be determined whether this increased activation of collicular fixation neurons is the result of a reduced inhibition from saccade-related neurons mediated by intracollicular inhibition (Munoz and Istvan, 1998) or whether fixation neurons receive an increased prestimulus excitation on anti-saccade trials from other neurons in the frontal cortex. One possible source may be SEF neurons that display an increased discharge on anti-saccade trials compared with pro-saccade trials (Schlag-Rey et al., 1997).

\section{Role of the FEF in the generation of anti-saccades}

This study has also demonstrated that saccade-related FEF neurons provide a movement signal for the anti-saccade. However, in contrast to SEF neurons (Schlag-Rey et al., 1997), the majority of FEF neurons had lower discharges for anti-saccades compared with pro-saccades. This finding is surprising. First, brain-imaging studies in humans have consistently demonstrated an increased activation of the FEF during anti-saccade tasks compared with pro-saccade tasks (O'Driscoll et al., 1995; Sweeney et al., 1996; Doricchi et al., 1997). Our data indicate that the population of saccade-related FEF neurons has a higher activity for prosaccades than for anti-saccades during all task periods (instruc- tion, stimulus, and saccade). One possible explanation for this discrepancy may be that the increased activation observed in imaging studies does not arise from an increased activation of saccade-related neurons, but from an increased activation of inhibitory interneurons within the FEF that suppress saccaderelated neurons. Second, the FEF is generally regarded as being involved in the generation of purposive voluntary saccades, whereas the SC is regarded as primarily involved in the generation of reflexive visually driven saccades (Guitton et al., 1985; Fischer, 1987; Schiller et al., 1987; Guitton, 1991; Dias et al., 1995; Forbes and Klein, 1996; Sommer and Tehovnik, 1997; Dias and Segraves, 1999). Our data, however, demonstrate that saccaderelated neurons in the SC and in the FEF share many attributes, including a higher saccade-related motor burst for pro-saccades compared with anti-saccades.

Based on the finding that saccade-related SC neurons have a lower level of neuronal pre-saccade activity for anti-saccades compared with pro-saccades, we have recently suggested that the FEF or SEF may provide additional signals for anti-saccades that bypass the SC (Everling et al., 1999). Although we have not attempted to identify corticopontine neurons in this study, it is known that half of the FEF neurons that project to the pons are movement neurons (Segraves, 1992). Therefore, given the likelihood that several neurons in our sample projected to the pons, it is unlikely that visuomovement or movement neurons in the FEF can compensate for the reduced input from the SC to the brainstem saccade generator for anti-saccades. This negative finding may support an important role of the SEF in the initiation of anti-saccades (Schlag-Rey et al., 1997).

Our study has demonstrated significant differences in the level of preparatory neuronal activity of FEF neurons between prosaccade and anti-saccade trials. Like in the SC, the task to suppress the prepotent response to look toward a flashed visual stimulus is accomplished in the FEF by a decrease of preparatory saccade-related activity. We hypothesize that an imbalance in favor of motor preparation over motor inhibition could lead to the high error rates in the anti-saccade task in various disorders with an underlying frontal lobe pathology (for review, see Everling and Fischer, 1998).

\section{REFERENCES}

Amador N, Schlag-Rey M, Schlag J (1998) Primate Antisaccades. I. Behavioral characteristics. J Neurophysiol 80:1775-1786.

Assad WF, Rainer G, Miller EK (1998) Neural activity in the primate prefrontal cortex during associative learning. Neuron 21:1399-1407.

Basso MA, Wurtz RH (1997) Modulation of neuronal activity by target uncertainty. Nature 389:66-69.

Basso MA, Wurtz RH (1998) Modulation of neuronal activity in superior colliculus by changes in target probability. J Neurosci 18:7519-7534.

Braun D, Weber H, Mergner T, Schulte-Mönting J (1992) Saccadic reaction times in patients with frontal and parietal lesions. Brain 115:1359-1386.

Bruce CJ, Goldberg ME (1985) Primate frontal eye fields. I. Single neurons discharging before saccades. J Neurophysiol 53:603-635.

Carpenter RHS (1981) Oculomotor procrastination. In: Eye movements: cognition and visual perception (Fischer DF, Monty RA, eds), pp 237-246. Hillsdale, NJ: Erlbaum.

Chen LL, Wise SP (1995a) Neuronal activity in the supplementary eye field during acquisition of conditional oculomotor associations. J Neurophysiol 73:1101-1121.

Chen LL, Wise SP (1995b) Supplementary eye field contrasted with the frontal eye field during acquisition of conditional oculomotor associations. J Neurosci 73:1122-1134.

Chen LL, Wise SP (1996) Evolution of directional preferences in the supplementary eye field during acquisition of conditional oculomotor associations. J Neurosci 16:3067-3081. 
Dias EC, Bruce CJ (1994) Physiological correlate of fixation disengagement in the primate's frontal eye field. J Neurophysiol 72:2532-2537.

Dias EC, Segraves MA (1999) Muscimol-induced inactivation of monkey frontal eye field: effects on visually and memory-guided saccades. J Neurophysiol 81:2191-2214.

Dias EC, Kiesau M, Segraves MA (1995) Acute activation and inactivation of macaque frontal eye field with GABA-related drugs. J Neurophysiol 74:2744-2748.

Doricchi F, Perani D, Inoccia C, Grassi F, Cappa SF, Bettinari V, Galati G, Pizzamigilio L, Fazio F (1997) Neural control of fast-regular saccades and antisaccades, an investigation using positron emission tomography. Exp Brain Res 116:50-62.

Dorris MC, Munoz DP (1998) Saccadic probability influences motor preparation signals and time to saccadic initiation. J Neurosci 18:7015-7026.

Dorris MC, Paré M, Munoz DP (1997) Neuronal activity in monkey superior colliculus related to the initiation of saccadic eye movements. J Neurosci 17:8566-8579.

Edelman JA, Keller E (1996) Activity of visuomotor burst neurons in the superior colliculus accompanying express saccades. J Neurophysiol 76:908-926.

Evarts EV, ShinodaY, Wise SP (1984) Neurophysiological approaches to higher brain functions. New York: Wiley.

Everling S, Fischer B (1998) The antisaccade: a review of basic research and clinical studies. Neuropsychologia 36:885-899.

Everling S, Dorris MC, Munoz DP (1998a) Reflex suppression in the anti-saccade task is dependent upon prestimulus neural processes. J Neurophysiol 80:1584-1589.

Everling S, Spantekow A, Krappmann P, Flohr H (1998b) Event-related potentials associated with correct and incorrect responses in a cued antisaccade task. Exp Brain Res 118:27-34.

Everling S, Dorris MC, Klein RM, Munoz DP (1999) Role of primate superior colliculus in preparation and execution of anti-saccades and pro-saccades. J Neurosci 19:2740-2754.

Fischer B (1987) The preparation of visually guided saccades. Rev Physiol Biochem Pharmacol 106:1-35.

Fischer B, Boch R (1983) Saccadic eye movements after extremely short reaction times in the monkey. Brain Res 260:21-26.

Fischer B, Weber H (1992) Characteristics of "anti" saccades in man. Exp Brain Res 89:415-424.

Forbes K, Klein RM (1996) The magnitude of the fixation offset effect with endogenously and exogenously controlled saccades. J Cognit Neurosci 8:344-352.

Fries W (1984) Cortical projections to the superior colliculus in the macaque monkey: a retrograde study using horseradish peroxidase. J Comp Neurol 230:55-76.

Funahashi S, Chafee MV, Goldman-Rakic PS (1993) Prefrontal neuronal activity in rhesus monkeys performing a delayed anti-saccade task. Nature 365:753-756.

Fuster JM (1991) The prefrontal cortex: anatomy, physiology, and neurophysiology of the frontal lobe. New York: Raven.

Goldberg ME, Bushnell MC (1981) Behavioral enhancement of visual responses in monkey cerebral cortex. II. Modulation in frontal eye fields specifically related to saccades. J Neurophysiol 46:773-787.

Gratton G, Coles MG, Sirevaag EJ, Eriksen CW, Donchin E (1988) Preand poststimulus activation of response channels: a psychophysiological analysis. J Exp Psychol Hum Percept Perform 14:331-344.

Guitton D (1991) Control of saccadic eye movements by the superior colliculus and basal ganglia. In: Eye movements (Carpenter RHS, ed). pp 244-276. London: Macmillian.

Guitton D, Buchtel HA, Douglas RM (1985) Frontal lobe lesions in man cause difficulties in suppressing reflexive glances and in generating goal-directed saccades. Exp Brain Res 58:455-472.

Hallett PE (1978) Primary and secondary saccades to goals defined by instructions. Vision Res 18:1279-1296.

Hallett PE, Adams BD (1980) The predictability of saccadic latency in a novel voluntary oculomotor task. Vision Res 20:329-339.

Hanes DP, Schall JD (1996) Neural control of voluntary movement initiation. Science 274:427-430.

Hebb DO (1972) Textbook of physiology, pp 77-93. Philadelphia: Saunders.

Hess WR, Burgi S, Bucher V (1946) Motor function of tectal and tegmental area. Monatsschr Psychiatr Neurol 112:1-52.

Ingle D (1973) Evolutionary perspectives on the function of the optic tectum. Brain Behav Evol 8:211-237.
Kupfermann I, Carew TJ, Kandel ER (1974) Local, reflex, and central commands controlling gill and siphon movements in Aplysia. J Neurophysiol 37:996-1019.

Lecas JC, Requin J, Anger C, Vitton N (1986) Changes in neuronal activity of the monkey precentral cortex during preparation of movement. J Neurophysiol 56:1680-1702.

Leichnetz GR, Spencer RF, Hardy SGP, Astruc K (1981) The prefrontal corticotectal projection in the monkey: an anterograde and retrograde horseradish peroxidase study. Neuroscience 6:1023-1041.

Lipski J (1981) Antidromic activation of neurones as an analytic tool in the study of the central nervous system. J Neurosci Methods 4:1-32.

Lynch JC, Hoover JE, Strick PL (1994) Input to the primate frontal eye field from the substantia nigra, superior colliculus and dentate nucleus demonstrated by transneuronal transport. Exp Brain Res 100:181-186.

Munoz DP, Istvan PJ (1998) Lateral inhibitory interactions in the intermediate layers of the monkey superior colliculus. J Neurophysiol 79:1193-1209.

Munoz DP, Wurtz RH (1995) Saccade-related activity in monkey superior colliculus. I. Characteristics of burst and buildup cells. J Neurophysiol 73:2313-2333.

Munoz DP, Broughton JR, Goldring JE, Armstrong IT (1998) Agerelated performance of human subjects on saccadic eye movement tasks. Exp Brain Res 121:391-400.

O'Driscoll GA, Alpert NM, Matthysse SW, Levy DL, Rauch SL, Holzman PS (1995) Functional neuroanatomy of antisaccade eye movements investigated with positron emission tomography. Proc Natl Acad Sci USA 92:925-929.

Paré M, Munoz DP (1996) Saccadic reaction time in the monkey: advanced preparation of oculomotor programs is primarily responsible for express saccade occurrence. J Neurophysiol 76:3666-3681.

Passingham R (1993) The frontal lobes and voluntary action. Oxford: Oxford UP.

Pierrot-Deseilligny CP, Rivaud S, Gaymard B, Agid Y (1991) Cortical control of reflexive visually-guided saccades. Brain 114:1472-1485.

Richmond BJ, Optican LM (1987) Temporal encoding of twodimensional patterns by single units in primate inferior temporal cortex. II. Quantification of response waveform. J Neurophysiol 57:147-161.

Riehle A, Requin J (1993) The predictive value for performance speed of preparatory changes in neuronal activity of the monkey motor and premotor cortex. Behav Brain Res 53:35-49.

Rivaud S, Müri RM, Gaymard B, Vermesch AI, Pierrot-Deseilligny C (1994) Eye movement disorders after frontal eye field lesions in humans. Exp Brain Res 102:110-120.

Robinson DA (1972) Eye movements evoked by collicular stimulation in the alert monkey. Vision Res 12:1795-1808.

Saslow MG (1967) Effects of components of displacement-setup stimuli upon latency for saccadic eye movements. J Opt Soc Am 57:1024-1029.

Schall JD (1991) Neuronal activity related to visually guided saccades in the frontal eye fields of rhesus monkeys: Comparison with supplementary eye fields. J Neurophysiol 66:559-579.

Schall JD (1997) Visuomotor areas of the frontal lobe. Cereb Cortex 12:527-638.

Schall JD, Thompson KG (1999) Neural selection and control of visually guided eye movements. Annu Rev Neurosci 22:241-259.

Schiller PH, Sandell JH, Maunsell JH (1987) The effect of frontal eye field and superior colliculus lesions on saccadic latencies in the rhesus monkey. J Neurophysiol 57:1033-1049.

Schlag-Rey M, Amador N, Sanchez H, Schlag J (1997) Antisaccade performance predicted by neuronal activity in the supplementary eye field. Nature 390:398-401.

Schmolesky MT, Wang Y, Hanes DP, Thompson KG, Leutgeb S, Schall JD, Leventhal AG (1998) Signal timing across the macaque visual system. J Neurophysiol 79:3272-3278.

Segraves MA (1992) Activity of monkey frontal eye field neurons projecting to oculomotor regions of the pons. J Neurophysiol 68:1967-1985.

Segraves MA, Goldberg ME (1987) Functional properties of corticotectal neurons in the monkey's frontal eye fields. J Neurophysiol 58:1387-1419.

Sherrington CS (1910) Notes on the scratch reflex of the cat. Q J Exp Physiol 3:213-220. 
Sommer MA (1994) Saccades elicited during visual scan in the monkey. Vision Res 34:2023-2038.

Sommer MA, Tehovnik EJ (1997) Reversible inactivation of macaque frontal eye field. Exp Brain Res 116:229-249.

Sommer MA, Wurtz RH (1998) Frontal eye field neurons orthodromically activated from the superior colliculus. J Neurophysiol 80:3331-3333.

Stanton GB, Goldberg ME, Bruce CJ (1988) Frontal eye field efferents in the macaque monkey: II. Topography of terminal fields in midbrain and pons. J Comp Neurol 271:493-506.

Sweeney JA, Mintun MA, Kwee S, Wiseman MB, Brown DL, Rosenberg DR, Carl JR (1996) Positron emission tomography study of voluntary saccadic eye movements and spatial working memory. J Neurophysiol 75:454-468.

Thompson KG, Hanes DP, Bichot NP, Schall JD (1996) Perceptual and motor processing stages identified in the activity of macaque frontal eye field neurons during visual search. J Neurophysiol 76:4040-4055.

Thompson KG, Bichot NP, Schall JD (1997) Dissociation of visual discrimination from saccade programming in macaque frontal eye field. J Neurophysiol 77:1046-1050.

Westheimer G (1954) Mechanisms of saccadic eye movements. Am Arch Opthalmol 52:710-724.

Wise SP, di Pellegrino G, Boussaoud D (1996a) The premotor cortex and nonstandard sensorimotor mapping. Can J Physiol Pharmacol 74:469-482.

Wise SP, Murray EA, Gerfen CR (1996b) The frontal cortex -basal ganglia system in primates. Crit Rev Neurobiol 10:317-356.

Wurtz RH, Mohler CW (1976) Enhancement of visual response in monkey striate cortex and frontal eye fields. J Neurophysiol 39:766-772. 